\title{
Serum beta 2-microglobulin and neopterin levels in children with febrile illness: their relation to influenza and febrile seizures
}

\author{
Akihisa Okumura ${ }^{1}$, Koji Takemoto ${ }^{2}$, Takao Ozaki ${ }^{2}$ \\ ${ }^{1}$ Department of Pediatrics, Nagoya University Graduate School of Medicine, Nagoya, Japan \\ ${ }^{2}$ Department of Pediatrics, Konan Showa Hospital, Japan
}

\begin{abstract}
The aim of this study is to evaluate serum beta 2-microglobulin and neopterin levels in children with febrile illness and to clarify their relation to influenza and febrile seizures (FS). We studied 34 patients with febrile illness whose age was between 1 and 6 years. Influenza $A$ antigen in the throat swab was positive in 17 patients (Flu group) and was negative in 17 (control group). Serum levels of beta 2 -microglobulin and neopterin were evaluated on admission. FS were observed in 13 patients ( 6 in Flu group and 7 in control group). Serum beta 2 -microglobulin and neopterin levels were higher in Flu group than in control group. On the other hand, there were no significant differences in serum beta 2-microglobulin or neopterin levels between those with and without FS. Higher serum beta 2microglobulin and neopterin levels in Flu group suggested that stronger activation of immune system was caused by influenza than by infection with other agents. (J Pediatr Neurol 2003; 1(1): 35-38).
\end{abstract}

Key words: influenza, febrile seizures, beta 2microglobulin, neopterin.

Correspondence: Akihisa Okumura, M.D.,

Department of Pediatrics, Nagoya University

Graduate School of Medicine

65 Tsurumai-cho, Showa-ku, Nagoya, Aichi, 466-8550, Japan.

Tel: +81-52-744-2309, fax: +81-52-744-2974

Email: okumura@med.nagoya-u.ac.jp

Received: May 4, 2003.

Revised: June 15, 2003.

Accepted: June 18, 2003.

\section{Introduction}

It is well known that influenza sometimes causes central nervous system complications. Febrile seizures (FS) are one of common complications of children with influenza. Influenza-related encephalopathy has been an important problem in Japanese children $(1,2)$. Immune system activation in patients with influenza has been vigorously investigated, especially in those complicated by encephalopathy. Some investigators revealed that high plasma concentration of IL- 6 could be related to the development of influenza-related encephalopathy $(3,4)$. On the other hand, the relation between FS and immune activation has not fully understood. One possible hypothesis is that the occurrence of FS may be associated with stronger immune activation. The measurement of various cytokines is desirable in order to solve this problem. However, the measurement of cytokines is not easily available in the usual clinical settings.

Beta 2-microglobulin (BMG) and neopterin are secondary products induced by some cytokines. The measurement of these substances is easily available in our institutes. Some authors described that serum levels of BMG and neopterin could be a marker of immune activation in patients with several viral infections such as human immuno-deficiency virus (5), cytomegalovirus $(6,7)$, or hepatitis C (8). We considered that serum levels of BMG and neopterin could be used as a marker of systemic immune activation also in patients with influenza.

The aim of this study was to determine whether systemic immune activation represented by serum BMG and neopterine levels was stronger in influenza than in other infections, and to determine whether more intense immune activation was observed in patients with FS than in those without FS. 
Table 1. Serum beta 2-microglobulin and neopterin levels in patients with and without influenza

\begin{tabular}{|c|c|c|c|}
\hline Parameters & $\begin{array}{l}\text { Flu } \\
\text { group } \\
\mathrm{n}=17\end{array}$ & $\begin{array}{l}\text { Control } \\
\text { group } \\
\mathrm{n}=17\end{array}$ & P-value \\
\hline Age (years) & $2.6 \pm 0.42$ & $2.2 \pm 0.37$ & NS \\
\hline \multicolumn{4}{|l|}{ Body } \\
\hline temperature $\left({ }^{\circ} \mathrm{C}\right)$ & $39.0 \pm 0.09$ & $39.1 \pm 0.10$ & NS \\
\hline Interval (days) & $1.6 \pm 0.35$ & $1.1 \pm 0.26$ & NS \\
\hline Febrile seizures & $6(35 \%)$ & $7(41 \%)$ & NS \\
\hline \multicolumn{4}{|l|}{ Serum BMG } \\
\hline level (mg/L) & $2.10 \pm 0.5$ & $1.75 \pm 0.11$ & $<0.05$ \\
\hline \multicolumn{4}{|l|}{ Serum NEO } \\
\hline level $(\mathrm{pmol} / \mathrm{mL})$ & $23.8 \pm 1.8$ & $14.0 \pm 1.7$ & $<0.01$ \\
\hline
\end{tabular}

BMG: beta 2-microglobulin; NEO: neopterin; NS: Non-significant.

\section{Materials and Methods}

Consecutive 45 patients with influenza-like illness were admitted to the Department of Pediatrics, Konan Showa Hospital during January through March 2001. Blood samples were obtained in order to measure serum BMG and neopterin levels on admission. Serum BMG level was measured by means of latex agglutination immunoassay and neopterin level by means of high performance liquid chromatography. Informed consent was obtained from the mothers of all patients.

Influenza A antigen in the nasal discharge was investigated on admission by rapid detection kit based on enzyme linked immunosorbent assay (Directigen Flu A). Influenza A antigen was positive in 17 patients. These patients were categorized into Flu group. Seventeen patients whose age was matched with those in the FS group were selected from the remaining 28 patients and categorized into control group. A 4-fold or more rise in hemagglutinin inhibition (HI) titer against influenza virus A (H3N2) was seen in 13 children in Flu group. A paired HI titer was not measured in the other 4 patients. In contrast, a significant rise in HI titer against influenza virus A (H3N2) was not observed in any patients in control group. A significant rise in $\mathrm{HI}$ titer against influenza virus A (H1N1) or influenza virus B was not seen in any patients in both groups.

FS was observed in 13 patients immediately before admission. FS was defined as a seizure associated with body temperature $>$ or $=38.5^{\circ} \mathrm{C}$ in the absence of a central nervous system infection, metabolic disturbance or acute electrolyte imbalance. No patient had seizures after admission. Other serious complications such as pneumonia or encephalopathy were not seen in any patients in
Table 2. Serum beta 2-microglobulin and neopterin levels in patients with and without febrile seizures

\begin{tabular}{|c|c|c|c|}
\hline Parameters & $\begin{array}{l}\text { FS (+) } \\
\mathrm{n}=13\end{array}$ & $\begin{array}{l}\text { FS (-) } \\
n=21\end{array}$ & P-value \\
\hline Age (years) & $2.2 \pm 0.43$ & $2.5 \pm 0.38$ & NS \\
\hline Body & & & \\
\hline temperature $\left({ }^{\circ} \mathrm{C}\right)$ & $39.0 \pm 0.10$ & $39.0 \pm 0.9$ & NS \\
\hline Interval (days) & $1.0 \pm 0.39$ & $1.6 \pm 0.25$ & NS \\
\hline $\begin{array}{l}\text { Flu antigen positive } \\
\text { Serum BMG }\end{array}$ & $6(46 \%)$ & $11(52 \%)$ & NS \\
\hline level (mg/L) & $1.79 \pm 0.13$ & $2.01 \pm 0.11$ & NS \\
\hline $\begin{array}{l}\text { Serum NEO } \\
\text { level }(\mathrm{pmol} / \mathrm{mL})\end{array}$ & $16.6 \pm 2.5$ & $20.4 \pm 1.9$ & NS \\
\hline
\end{tabular}

FS: febrile seizures; BMG: beta 2-microglobulin;

NEO: neopterin; NS: Non-significant.

both groups.

Statistical analysis between two groups was performed by means of unpaired t-test for quantitative variables and Fisher's exact test for qualitative variables. Quantitative variables were shown as the mean \pm standard errors of the mean. Statistical significance was accepted at the level of $\mathrm{P}<0.05$.

\section{Results}

The age of the patients ranged from 1 to 6 years (average 2.4 years). The average interval between the onset of fever $>38^{\circ} \mathrm{C}$ and admission was 1.2 days (range 0-4 days). Psychomotor development and neurological findings were normal in all patients. FS was observed in 6 children in Flu group and in 7 in control group. There was no significant difference in the age, the interval between the onset of fever and admission, and the body temparature on admission between Flu and control groups. Serum BMG levels were significantly higher in Flu group $(2.10 \pm 0.12 \mathrm{mg} / \mathrm{L})$ than in control group $(1.75 \pm 0.11$ $\mathrm{mg} / \mathrm{L}, \mathrm{p}<0.05)$. Serum neopterin levels were also significantly higher in Flu group $(23.8 \pm 1.8 \mathrm{pmol} /$ $\mathrm{mL})$ than in control group $(14.1 \pm 1.8 \mathrm{pmol} / \mathrm{mL}, \mathrm{p}$ $<0.01$ ) (Table 1).

There was no significant difference in the age, the interval between the onset of fever and admission, and the body temparature on admission between patients with and without FS. Serum BMG levels were not significantly different between those with FS $(1.79 \pm 0.13 \mathrm{mg} / \mathrm{L})$ and those without FS $(2.01 \pm 0.11 \mathrm{mg} / \mathrm{L})$. Serum neopterin levels were not significantly different between those with FS (16.6 $\pm 2.5 \mathrm{pmol} / \mathrm{mL})$ and those without FS $(20.4 \pm 1.9$ $\mathrm{pmol} / \mathrm{mL}$ ) (Table 2). 


\section{Discussion}

Immune activation is closely related to diverse forms of central nervous system disorders. Some cytokines are considered to play an important role in the development of encephalopathy related to influenza infection $(3,4)$, although its pathogenesis has not been fully understood. Evaluation of immune activation will be necessary to clarify the relation between central nervous system disorders and influenza. However, it is not easy to understand the role of each cytokine, because there are many kinds of cytokines that may participate in the development of central nervous system disorders, and their interactions are very complicated. Cytokines induce the production of some second products such as BMG and neopterin. The production of BMG and neopterin is induced mainly by interferon-gamma released by activated $\mathrm{T}$ cells. Their levels reflect the activation of cellmediated immunity. Thus, the measurement of BMG and neopterin will be useful to evaluate activity of cell-mediated immunity in patients with central nervous system disorders associated with influenza or other infection diseases. Griffin et al. (9) reported that plasma levels of neopterin were higher in children with measles than in children with other infectious diseases. They also showed that measles children complicated by autoimmune encephalomyelitis had higher neopterin levels than those with uncomplicated disease (9). Some authors demonstrated that serum levels of BMG and neopterin were elevated in patients with acute Epstein-Barr virus infection $(10,11)$. The prognostic value of $B M G$ and neopterin was vigorously investigated in children with HIV infection $(12,13)$.

It will be important that serum BMG and neopterin levels were higher in patients with influenza, even without serious complications such as encephalopathy, than in those with infections other than influenza. This result is consistent with the study by Cooper et al. (14) which revealed that influenza $\mathrm{A}$ infection was associated with increases in serum BMG concentration, although only slight increase was seen in infectious mononucleosis and cytomegalovirus infection. These facts suggest that influenza my cause strong immune activation even in patients without serious complications. This may be related to the development of central nervous system involvement in patients with influenza. However, further studies are necessary to clarify the clinical usefulness of the measurement of serum BMG and neopterin levels in patients with influenza.

Serum BMG and neopterin levels were not significantly different between patients with and without FS in this study, although Kawakami et al. (15) revealed increased cerebrospinal fluid neopterin levels in patients with FS. They reported that cerebrospinal fluid levels of neopterin weresignificantly higher in patients with FS than in those with pyrexia without convulsions or convulsions without pyrexia. The cerebrospinal fluid neopterin /serum neopterin ratio was also higher in patients with FS than in those with pyrexia without convulsions or convulsions without pyrexia. There may be some explanation for this discrepancy. Firstly, we did not measure cerebrospinal fluid levels of BMG and neopterin. There is a possibility that cerebrospinal fluid levels of these substances may not be parallel to serum levels. Millner et al. (16) reported that cerebrospinal fluid levels of neopterin were specifically elevated in central nervous system infections, while serum levels of neopterin were lower in central nervous system infection than in peripheral infections. Werner-Felmayer et al. (17) showed that human microglia cells were able to produce measurable amount of neopterin. Secondly, the occurrence of FS was more closely related to some other factors such as genetic predisposition. It is well-known that FS occur with increased frequency among family members of patients with FS. Family history of FS in a first degree relative is a factor that predict a first FS and recurrence after a first FS (18). Several gene mutations related to FS have been established in recent years (19-21). These facts indicate that genetic factors will play an etiological role in the occurrence of FS. The susceptibility of FS can vary among individuals, even if the degree of activation of immune system were similar among them.

In conclusion, our study indicated that serum BMG and neopterin were higher in patients with influenza than in those without influenza. However, they were not different between those with and without FS. More detailed studies are necessary in order to understand the clinical significance of serum BMG and neopterin in patients with febrile illness.

\section{References}

1. Kasai T, Togashi T, Morishima T. Encephalopathy associated with influenza epidemics. Lancet 2000; 355: $1558-1559$

2. Morishima T, Togashi T, Yokota S, et al. Encephalitis and encephalopathy associated with an influenza epidemic in Japan. Clin Infect Dis 2002; 35: 512517

3. Ito $\mathrm{Y}$, Ichiyama $\mathrm{T}$, Kimura $\mathrm{H}$, et al. Detection of influenza virus RNA by reverse transcription-PCR and proinflammatory cytokines in influenza-virusassociated encephalopathy. J Med Virol 1999; 58: 420-425.

4. Aiba H, Mochizuki M, Kimura M, Hojo H. Predictive value of serum interleukin-6 level in influenza virusassociated encephalopathy. Neurology 2001; 57: 
295-299.

5. Fahey JL, Taylor JM, Detels R, et al. The prognostic value of cellular and serologic markers in infection with human immunodeficiency virus type 1 . N Engl J Med 1990; 322: 166-172.

6. Backman L, Ringden O, Bjorkhem I, Lindback B. Increased serum beta 2 microglobulin during rejection, cyclosporine-induced nephrotoxicity, and cytomegalovirus infection in renal transplant recipients. Transplantation 1986; 42: 368-371.

7. Jungraithmayr TC, Reschke M, Grebe SO, Lange H, Radsak K, Mueller TF. Assessment of cytomegalovirus infections using neopterin and a new immunoblot. Clin Chim Acta 2001; 310: 63-69.

8. Fuchs D, Norkrans G, Wejstal R, et al. Changes of serum neopterin, beta 2-microglobulin and interferon-gamma in patients with chronic hepatitis C treated with interferon-alpha 2b. Eur J Med 1992; 1: 196-200.

9. Griffin DE, Ward BJ, Jauregui E, Johnson RT, Vaisberg A. Immune activation during measles: interferon-gamma and neopterin in plasma and cerebrospinal fluid in complicated and uncomplicated disease. J Infect Dis 1990; 161: 449-453.

10. Ibsen KK, Krabbe S, Hesse J. Beta 2-microglobulin serum levels in infectious mononucleosis in childhood. Acta Pathol Microbiol Scand 1981; 89: 205-208.

11. Schuster V, Herold M, Wachter H, Reibnegger G. Serum concentrations of interferon gamma, interleukin-6 and neopterin in patients with infectious mononucleosis and other EpsteinBarr virus-related lymphoproliferative diseases. Infection 1993; 21: 210-213.

12. Di Franco MJ, Zaknun D, Zaknun J, et al. A prospective study of the association of serum neopterin, beta 2-microglobulin, and hepatitis $B$ surface antigenemia with death in infants and children with HIV-1 disease. J Acquir Immune Defic Syndr 1994; 7: 1079-1085.
13. Eley BS, Hughes J, Potgieter S, Keraan M, Burgess $\mathrm{J}$, Hussey GD. Immunological manifestations of HIV-infected children. Ann Trop Paediatr. 1999; 19: 3-7.

14. Cooper EH, Forbes MA, Hambling MH. Serum beta 2-microglobulin and $\mathrm{C}$ reactive protein concentrations in viral infections. J Clin Pathol 1984; 37: 1140-1143.

15. Kawakami Y, Fukunaga Y, Kuwabara K, Fujita T, Fujino O, Hashimoto K. Clinical and immunological significance of neopterin measurement in cerebrospinal fluid in patients with febrile convulsions. Brain Dev 1999; 21: 458-460.

16. Millner MM, Franthal W, Thalhammer GH, et al. Neopterin concentration in cerebrospinal fluid and serum as an aid in differentiating central nervous system and peripheral infections in children. Clin Chem 1998; 44: 161-167.

17. Werner-Felmayer G, Werner ER, Fuchs D, Hausen A, Reibnegger G, Wachter H. Characteristics of interferon induced tryptophan metabolism in human cells in vitro. Biochim Biophys Acta 1989; 1012: 140-147.

18. Camfield P, Camfield C, Kurlemann G. Febrile seizures. In: Roger J, Bureau M, Dravet $\mathrm{CH}$, Genton P, Tassinari CA, Wolf P (eds). Epileptic Syndromes in Infancy. Childhood and Adolescence ( $3^{\text {rd }}$ ed). Eastleigh: John Libbey, 2002, pp 145-152.

19. Wallace RH, Scheffer IE, Barnett S, et al. Neuronal sodium-channel alphal-subunit mutations in generalized epilepsy with febrile seizures plus. Am J Hum Genet 2001; 68: 859-865.

20. Escayg A, MacDonald BT, Meisler $\mathrm{MH}$, et al. Mutations of SCN1A, encoding a neuronal sodium channel, in two families with GEFS +2 . Nat Genet 2000; 24: 343-345.

21. Baulac S, Huberfeld G, Gourfinkel-An I, et al. First genetic evidence of GABA(A) receptor dysfunction in epilepsy: a mutation in the gamma2subunit gene. Nat Genet 2001; 28: 46-48. 